\title{
GLL
}

Geomatics, Landmanagement and Landscape No. $4 \cdot 2021,19-29$

\section{GIS TOOLS FOR LANDSCAPE CHARACTER ASSESSMENT: CASE OF ZIBAN REGION IN ALGERIA}

\author{
Asma Menasra, Soumia Bouzaher
}

\begin{abstract}
Summary
Landscape is an area formed by the interactions between humans and nature, which bring various characteristics to the area. Landscape Character Assessment (LCA) methods enable more accurate description, mapping, and evaluation of features within the landscape. Also, landscape characterization and classification is facilitated by the advances of Geographic Information Systems (GIS), which constitute a very efficient tool for analysis and overlay mapping. This paper explores and tests an application of Landscape Character Assessment (LCA) methodology at a regional scale in Ziban region, Algeria, combining natural and cultural attributes using GIS. The first stage of overlay of attributes is followed by the verification of draft map involving a visual assessment on-site in order to develop the final classification and assessment describing each landscape character area and type. The study results show that Ziban region has a rich structure with diversified landscapes created by unique natural and cultural landscape values composed of 36 different character areas and 19-character types. The main contribution of this research consists in developing a typology for Ziban landscape and providing useful results for decision-making related to the future management of landscape character in the Algerian context, which has undergone strong pressure related to urbanization, industry, transport, desertification, and tourism.
\end{abstract}

\section{Keywords}

Geographic Information Systems (GIS) • landscape character assessment • landscape • Ziban region $\bullet$ landscape character types $\bullet$ landscape character areas

\section{Introduction}

The advances of Geographic Information Systems (GIS) techniques provide important opportunities for more effective decision making in the context of landscape protection and planning. It has significantly improved mapping of landscape character and supported the objective characterization [Nick et al. 2013, Meryem et al. 2017]. Furthermore, Geographic Information Systems is now considered to be a prime tool for exploring the typology of landscapes, as it encompasses a set of essential tools for spatial data collection, management, analysis, and visualization [Paul et al. 2005, Stefan and Geoffrey 2009, Yu et al. 2019]. 
Landscape Character Assessment (LCA) is one of the fields which have greatly benefited from GIS technology [Nick et al. 2013], and is now largely used by planners, decision makers, and managers. The overarching goal is to understand the different landscape characters, in order to enhance environmental management and protection [Meryem et al. 2016].

Landscape Character Assessment (LCA) is the process of mapping, describing and evaluating landscapes on the basis of the presence and arrangement of different landscape features using geospatial information techniques, such as GIS [Carys 2002, André et al. 2009].

As a process, LCA works at a range of scales i.e., national, regional, and local [Dirk 2005], and it includes main phases of pre-classification, field study, and mapping landscape character areas and landscape types [Meryem et al. 2017] through a combination of natural and cultural factors of the landscape [Trond et al. 2018].

An initial literature review on LCA revealed a variety of applications using Geographic Information Systems (GIS) for various purposes in many countries, particularly in Europe, UK and Ireland [Cary's 2002, Sam 2005, Heritage Council 2006] and other countries such as Hong Kong, South Korea, New Zealand [Planning Department 2008, Keun-Ho and Stephan 2007, Lars 2009]. There are few LCA applications in the Mediterranean countries, Turkey, Tunisia, and Cyprus [Ioannis and Louis 2007, Steven et al. 2008, Osman et al. 2011, Nilgun et al. 2015].

As a Mediterranean country, Algeria has not yet adopted LCA method as a tool for characterizing its landscapes. Algeria is the largest African country and has a great diversity of natural and cultural landscapes. It has undergone a number of changes in traditional landscapes related to urbanization pressures, industry, transport, desertification, and tourism. Consequently, the regional diversity has been adversely affected, and the new landscapes that were thus created threaten the distinct character of its territory [Soumia 2015].

In this regard, the objective of the present work is to identify and test landscape character assessment methodology using a geographic information system (GIS) in Ziban region of Algeria. The study is important at the regional level. Some adjustments for LCA methodology developed in Europe were necessary in order to account for some differences in the Algerian context.

The findings of this particular study can be used for land use planning and management in the region of Ziban, and therefore can considerably reduce the time and material resources devoted to finding typology of landscapes and their character.

\section{Material and methods}

\subsection{Study area}

The Ziban region was chosen for this study, as an example of the Northern Sahara region in Algeria, for its attractiveness. The main Ziban city is Biskra, located in the Southeast part of Algeria (Fig. 1), between the $34^{\circ} 38^{\prime}$ and $35^{\circ} 5^{\prime}$ North latitude, $4^{\circ} 56^{\prime}$ and $5^{\circ} 35^{\prime}$ East longitude. The total area of the Ziban region is $21,671 \mathrm{~km}^{2}$. 
Ziban region has a great variety of landscapes due to its location on the Southern foothills of the Saharan Atlas. It consists of high mountains in the northern limit, and arid character of plains and plateaus in the south towards the Sahara. This variety reflects the differences in biophysical conditions and long cultural history.

Ziban is located in the Saharan bioclimatic zone. It is characterized by moderate temperate in the winter, whereas summers are hot and dry. The climatic conditions of the region favor a diversified agricultural landscape characterized by palm groves, which affect the entire structure of human settlements [Soumia 2018]. Other practices are also present - such as open fields producing aromatic and medicinal plants, vegetable cultivation, cereals, and olive groves.

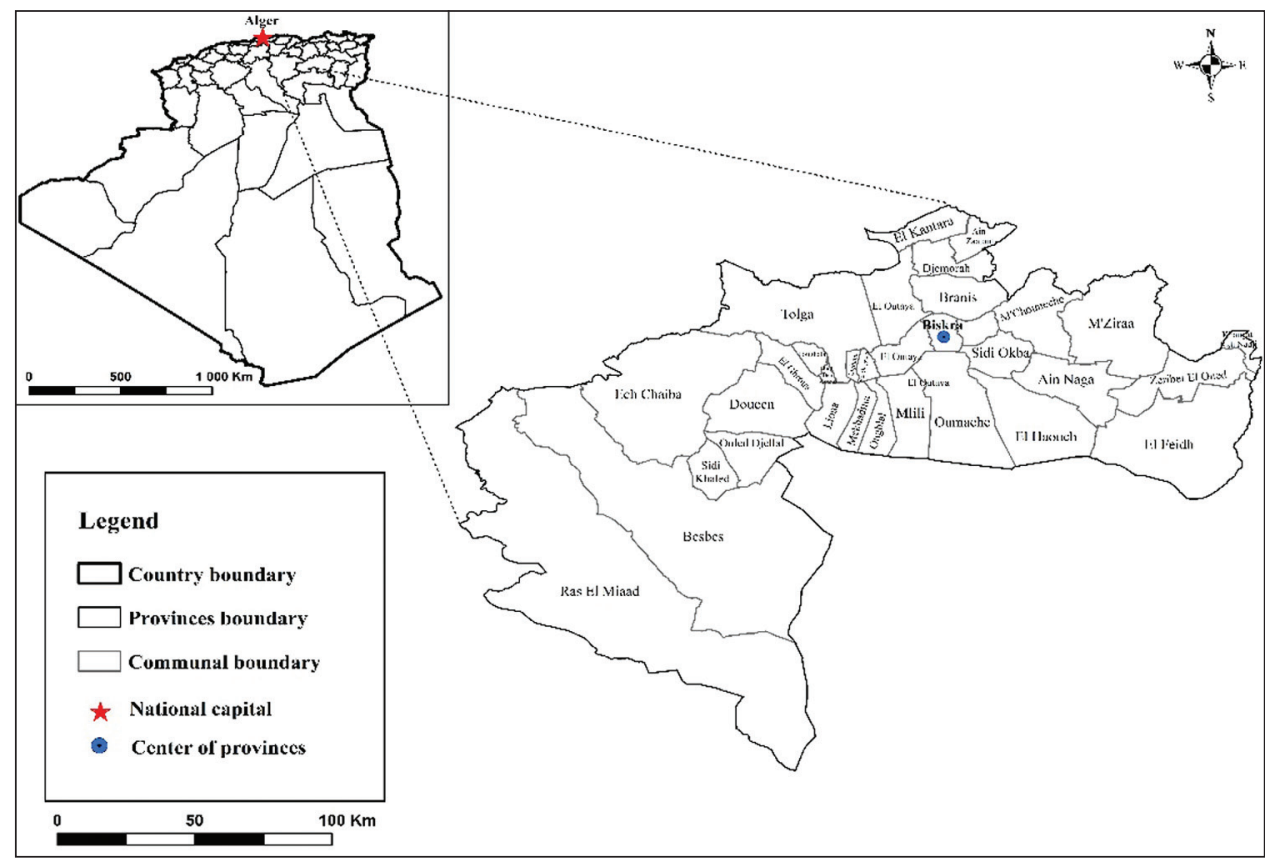

Source: Authors' own study

Fig. 1. Location of research area, Ziban region

\subsection{Methodology of the study}

The present paper defines the exemplar methodology of landscape character assessment (LCA) using Geographical Information Systems (GIS), as applied to the Ziban landscapes, and carried out at a regional level.

In the present study, the variables for LCA were selected from previously published works [Keun-Ho and Stephan 2007, Cary's 2002, Meryem et al. 2015] and were inspired by the characteristics of the Ziban region. 
The method involves integrating map-based physical and cultural data as well as visual assessment on-site, as it has three main phases: (1) pre-classification: determination of the attributes and selection of the databases on GIS; (2) field study; and (3) final classification of the Landscape Character Areas and Types (Fig. 2). These phases are explained below in detail.

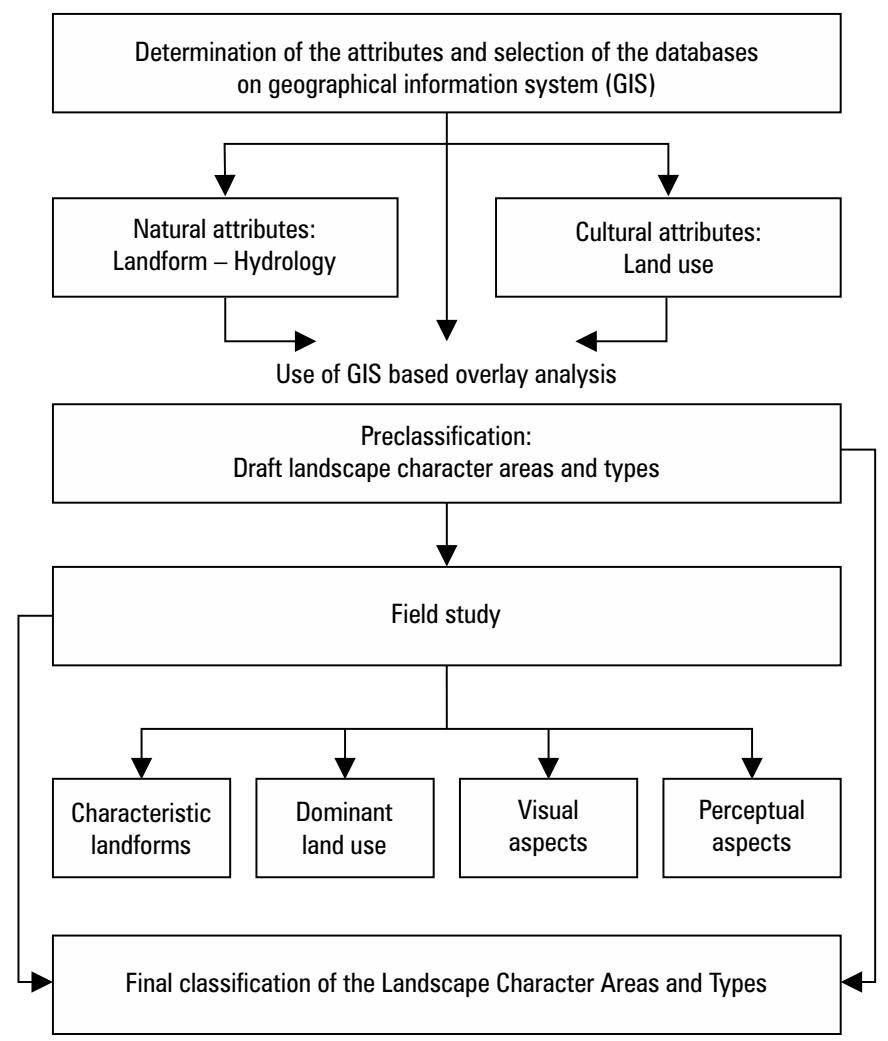

Source: Authors' own study

Fig. 2. Key steps of the study

Pre-classification: Determination of the attributes and selection of the databases on geographical information systems (GIS)

The mapping process includes geodatabase creation, reclassifying it, and overlaying different layers on geographic information system to create a draft map of landscape character areas and types - as applied to Ziban region.

The main databases on which the classification of the landscape was based were the topographic contour map and land use designation. We note that the topography and the hydrographic network (Wadis) were extracted from an analysis performed using a Digital Elevation Model (DEM), downloaded from the USGS website at the spatial 
resolution of 50 meters. For the Land use map of Ziban region (2015), scale 1:250,000 was digitized to produce a map with the associated databases.

The data for these attributes were stored, processed, interpreted, and overlay in a hierarchical system using Geographical Information Systems (GIS).

Each datum represents a polygon, and was subjected to overlay analysis using the "ArcGIS10.8" software application. Mapping of landscape character areas was performed visually on-screen through an iterative process of sub-division of polygons. Polygons with the same characteristics have been grouped to achieve the common types of landscape characters.

The attributes are a combination of natural and cultural factors that have shaped the landscape of Ziban region. Details of land uses were identified under the following classes: built-up area, agriculture area, palm groves, forest, scrubland, water bodies, barren land, mountains and rocky areas, wasteland; and four landform classes based on mountains, plain, plateau, and depression.

As a result, a thematic map at a scale of 1:250,000 sub-divided Ziban region into a series of landscape character areas, which are characterized by unique features and reflect geographical characteristics of the region.

Field study

A site survey work was conducted in order to validate the draft landscape character areas and types selected at the previous stage using GIS. In addition, site gathering characterization and description for each landscape area and type was performed. A structured field survey sheet was filled in, using landscape character features to record observations about landscape elements, characteristic landforms, and dominant land use, as well as visual and perceptual aspects.
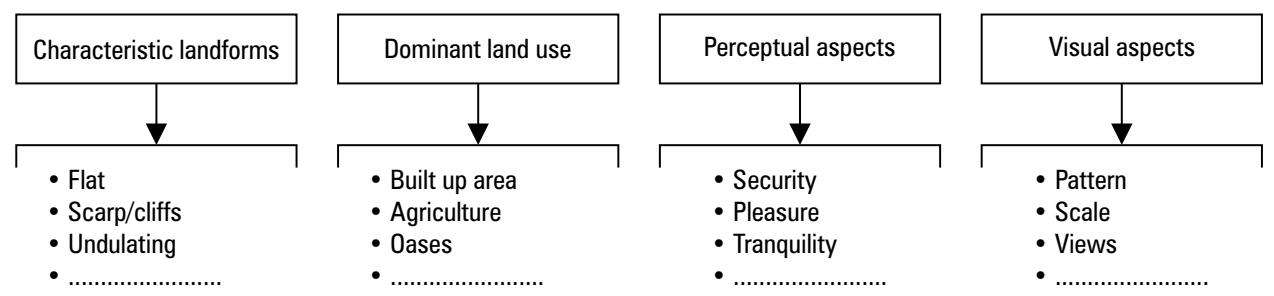

Source: inspired by Cary's [2002]

Fig. 3. The set of features for visual assessment of landscape characters

The final classification of the Landscape Character Areas and Types

The outputs of mapping process using Geographical Information Systems (GIS) and field surveys analysis were integrated together to prepare a final map of landscape areas and types. In this map, respective landscape character areas and types are described, accompanied by their key characteristics and features. 
The naming of landscape character types was derived from the dominant influence on landscape character, and often the wording relates to landform and land use [Christine 2014] such as Agricultural and settled plateau, dense settled plain. In contrast, the landscape character areas were defined through a place name or established locality [Christine 2014].

\section{Results and discussion}

The use of GIS tools for landscape character mapping in Ziban region identified 36 landscape character areas. Subsequently, these areas were grouped into 19 landscape character types (Fig. 4).

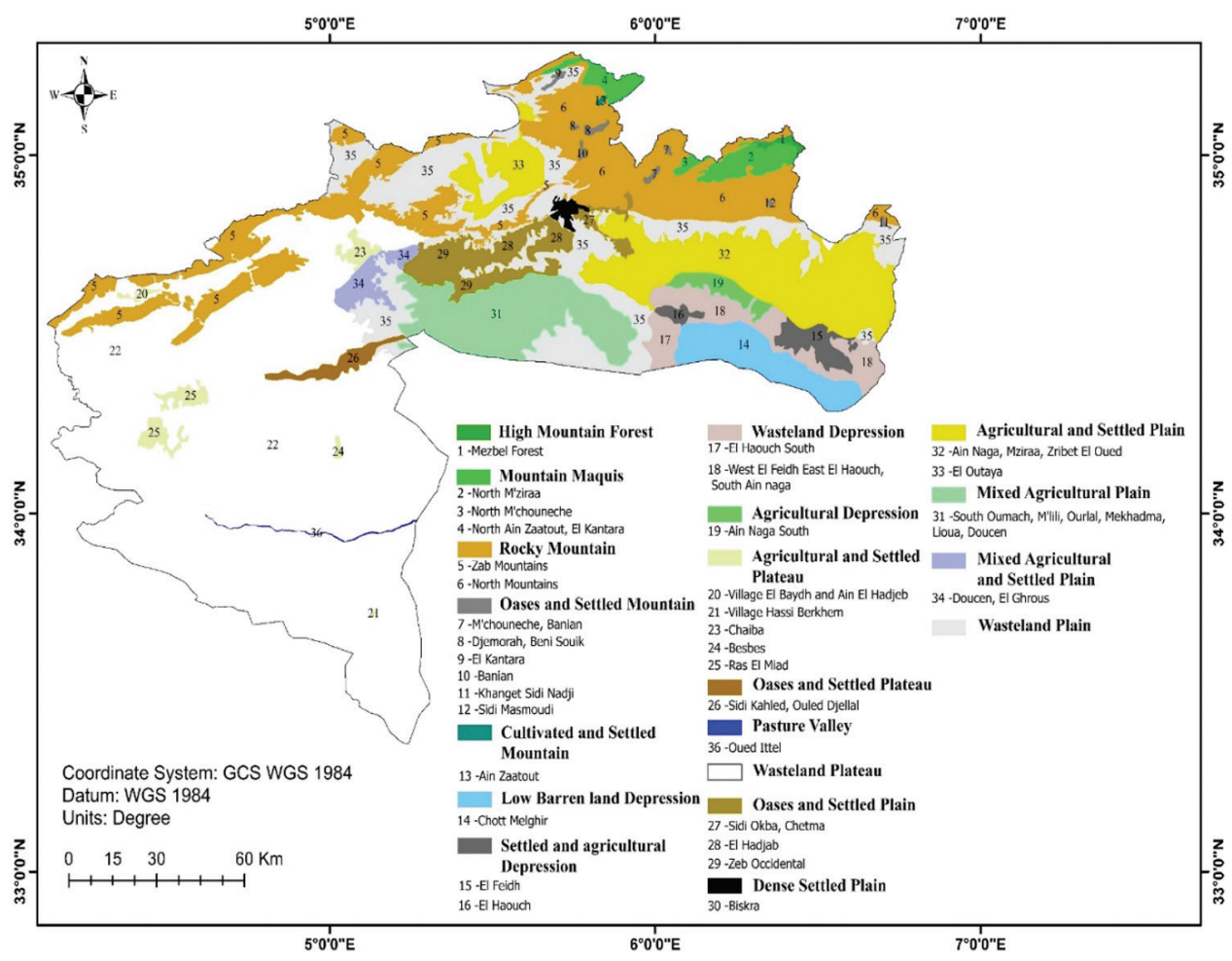

Source: Authors' own study

Fig. 4. Map of landscape character areas and types in Ziban region

Overall, the landscape of Ziban region is extremely rich and diversified. It can be broadly divided into four distinct regions: the northern and western mountains (forested mountains, oases and settled mountains, cultivated and settled mountains, mountain maquis, and rocky mountains); the plateau (agricultural and settled plateau, oases and 
settled plateau, wasteland plateau); the plain (oases and settled plain, dense settled plain, agricultural and settled plain, mixed agricultural plain, and wasteland plain); as well as depression landscape. These landscape types reflect their unique character, each with its own natural and cultural features and each one represents one or more landscape areas. Oases and agricultural land are some particular examples (Fig. 4.)

Generally, urban development, oases and agriculture are the important traits in the landscape character types of Ziban region, developed on plain, mountains, and plateaus. For instance, in the dense settled plain, landscape character type was a typical settlement pattern (Fig. 5). Urban housing and human settlements occur in many different forms and were characterized by medium height with a mixed use (commercial activity in the ground floor, and residential dwellings above).

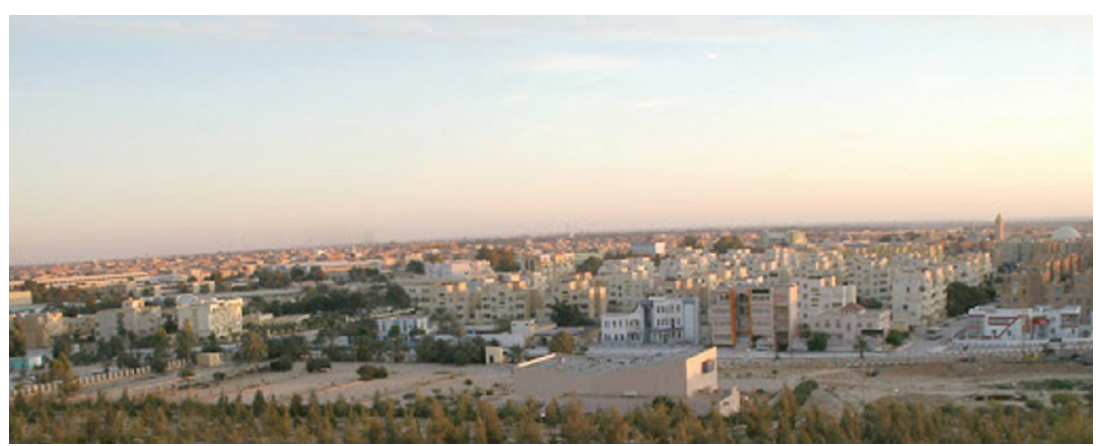

Photo: http://www.algerie-monde.com/villes/biskra/

Fig. 5. Dense settled plain landscape character type

Furthermore, other important character types, such as oases, and agricultural landscapes, have significant natural and cultural value. Most of the oasis landscape character types spread in cultivated valleys with intensive palm groves (Fig. 6). These character types bear witness to both historical references and traditional land use patterns in the Ziban region, based on palm grove cultivation and other practices.

Agricultural landscape character types were intensively cultivated, associated with different farming systems, such as aromatic and medicinal plants, irregular and regular fields of market gardening and cereals.

Moreover, the Ziban region was subcategorized into several landscape character areas of strong 'personalities'. These areas are unique and geographically specific, with landscape types defined by an individual character and identity [Heritage Council 2006, p. 78, Natural England 2014, p. 56]. The majority of the landscape character areas are determined by their geographical, natural, and cultural features. The following examples illustrate this diversity.

The landscape character area No 26 (Sidi Kahled and Ouled Djellal) is a slightly undulating plateau area with wide filtered views of the palm groves in a linear arrange- 
ment according to Wadi Djedi. The vegetation cover in this area is poor except for the shrubs and other Saharan plants, appearing along the Wadi and characterized by an important grazing activity. It is a dense settled area with a mix of different styles, mostly modern, but also including vernacular buildings. In addition, irrigation techniques using traditional wells and sequoias, and crops under palm trees are still practiced.



Photo: http://www.algerie-monde.com/villes/biskra/

Fig. 6. Oasis landscape character type

The landscape character area No 32 (Ain Naga, Mziraa, Zribet El-Oued) covers the whole of the flat plain punctuated by mainly nucleated human settlements associated with open fields. It is an area of intensive agriculture dominated by open fields of cereals, market gardening, and industrial crops.

Some areas have a high historical and cultural value, such as landscape character area No 9 (El Kantara). It is a slightly hilly area cut in two by a wide valley (Wadi El Hay), surrounded by extremely steep mountains to the north, which form gorges (Fig. 7). In addition, it is characterized by cultivated valleys with concentrated palm groves and other crops (olive groves and fruit trees). Human settlements extend on both banks of the Wadi, and they include a mixture of different styles, including the vernacular building (red village). This area is culturally very diverse with vestiges of the Roman occupation, which are prolific in places such as the Roman Bridge. Typical local architecture is found in the Red Village and the European City. This area is associated with many museums, a recurring feature constantly reminiscent of the origins of this landscape. 

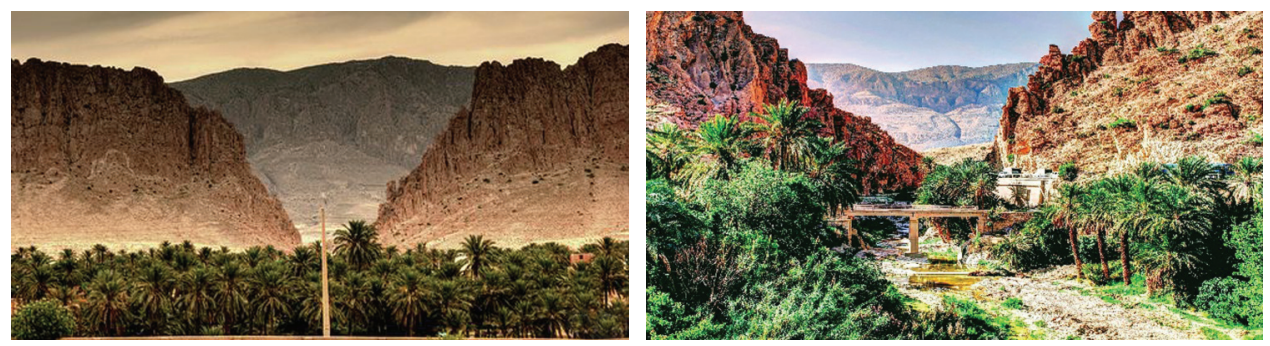

Photo: http://www.algerie-monde.com/villes/biskra/

Fig. 7. El Kantara landscape character area

\section{Conclusions}

The result of the study demonstrates that the use of GIS as a support tool greatly enhances the production of landscape character assessment. This technology provides significantly increased opportunities for more detailed landscape typology and plan analyses, which are more accurate and faster.

The present work explored the landscape typology of Ziban region based on landscape character assessment (LCA), which was one of the methods keys for determining the 19 landscape character types and 36 landscape character areas. Using GIS, both natural (landform, water body) and cultural (land use) data that reflect landscape character were examined. The results highlight the strong influence of the landform and land use, and reflect the diversity of landscape types, the most important of which are settled oasis landscape and settled agricultural landscapes. Moreover, this process is extremely important for decision makers in terms of forming future landscape plans that offer alternatives for monitoring future changes.

An important component of this study indicates the successful application of landscape character assessment (LCA) to other contexts with different cultural and natural characteristics. Last but not least, the need for further landscape research is very important in Algeria considering the richness, diversity, and the recent landscape changes.

\section{References}

André J., Derk-Jan S., Jeroen C.J.G., Walter A.H.R. 2009. Landscape character assessment using region-growing techniques in geographical information systems. J. Environ. Manag., 90, S161-S174.

Cary's S. 2002. Landscape Character Assessment. Guidance for England and Scotland. Countryside Agency, Cheltenham/Scottish National Heritage, Edinburgh.

Christine T. 2014. An Approach to Landscape Character Assessment. Natural England, Worcester, UK.

Dirk M.W. 2005. European landscape character areas: typologies, cartography, and indicators for the assessment of sustainable landscapes. Final ELCAI Project Report, Landscape Europe. 
Heritage Council. 2006. Landscape Character Assessment (LCA) in Ireland: Baseline Audit and Evaluation. Final Report to the Heritage Council. Heritage Council, Kilkenny, Ireland.

Ioannis V., Louis F. C., 2007. Coastal Landscapes of Tunisia with special focus on Cap Bon: A Proposed Landscape Character Assessment. UNEP PAP/RAC.

Keun-Ho K., Stephan P. 2007. Landscape Character, Biodiversity and Land Use Planning: The Case of Kwangju City Region, South Korea. Land Use Policy, 4, 264-274.

Lars B. 2009. Classifying landscape character. Landscape Research, 34(3), 299-321.

Meryem A., Rabia I., Veli O., Emrah Y. 2015. Definition of landscape character areas and types in Side region, Antalya-Turkey with regard to land use planning. Land Use Policy, 44, 90100.

Meryem A., Rabia I., Veli O. 2016. Clusters of landscape characters as a way of communication in characterisation: A study from side, Turkey. Journal of Environmental Management, 182, 385-396.

Meryem A., Rabia I., Veli O., Emrah Y. 2017. Exploring a combination of objective and subjective assessment in landscape classification: Side case from Turkey. Applied Geography, 83, $130-140$.

Nick S., Ioannis V., Geoffrey G., Steven W., Vasso V., Maria Z., Vassilis T. 2013. Geospatial tools for Landscape Character Assessment in Cyprus. Proceedings of SPIE. The International Society for Optical Engineering.

Nilgun G., Cengiz A., Abdul-Aziz G., Mustafa D., Fevzi K. 2015. Coastal land degradation and character assessment of Southern Black Sea landscape. Ocean \& Coastal Management, 118, 282-289.

Osman U., Figen D., Gulay Ç., Fusun E., Sebahat A. 2011. National and Regional Landscape Classification and Mapping of Turkey: Konya Closed Basin, Sula Lake and its Surrounding Area. International Journal of the Physical Sciences (IJPS), 6(3), 550-565.

Paul A.L., Michael F.G., David J.M., David W.R. 2005. Geographic Information Systems and Science ( $2^{\text {nd }}$ ed.). Wiley, Chichester.

Planning Department. 2008. Landscape Value Mapping of Hong Kong - Technical Report 2. Technical Report by the Government of Hong Kong Special Administrative Region of the People's Republic of China. http://www.pland.gov.hk

Sam T. 2005. Devon Historic Landscape Characterisation. Devon County Council Historic Environment Service/English Heritage, Exeter.

Soumia B. 2015. Un aménagement durable pour un projet écotouristique, cas des Ksours de la micro région des Ziban. Le redressement d'un circuit écotouristique. Thèse de doctorat àl'université de Biskra.

Soumia B. 2018. Le paysage oasien entre perception et réalité. digit AR: Revista Digital de Arqueologia, Arquitectura e Artes, 5.

Stefan S., Geoffrey J.H. 2009. Free and open-source geographic information tools for landscape ecology. Ecol. Inf., 4 (4), 183-195.

Steven W., Geoffrey G., Ioannis V. 2008. Cyprus landscape mapping project. Final Report. Landscape Mapping Group, University of Reading, 31.

Trond S., Rune H., Lars E. 2018. Methods for landscape characterization and mapping: A systematic review. Land Use Policy, 75, 557-569.

Yu H., Liu X., Kong B., Li R., Wang G. 2019. Landscape ecology development supported by geospatial technologies: A review. Ecological Informatics, 51, 185-192. 
PhD Asma Menasra University of Biskra

Department of Architecture, Laboratory LACOMOFA, Algeria

e-mail: asma.menasra@univ-biskra.dz ORCID: 0000-0003-3755-3330

Prof. Soumia Bouzaher University of Biskra

Department of Architecture, Laboratory LACOMOFA, Algeria

e-mail: s.bouzaherlalouani@univ-biskra.dz 